\title{
CLIMATOLOGIA SINÓPTICA DOS GRANDES INCÊNDIOS FLORESTAIS (> 5.000 HA) EM PORTUGAL CONTINENTAL
}

\author{
BOTELHO, Filipe Miguel - fmlbotelho@hotmail.com \\ Centro de Estudos em Geografia e Ordenamento do Território - Universidade do \\ Minho/Portugal \\ FERREIRA-LEITE, Flora - floraferreiraleite@gmail.com \\ Centro de Estudos em Geografia e Ordenamento do Território - Universidade do \\ Minho/Portugal \\ SILVA, Nuno Ganho Gomes da - nganho@netvisao.pt \\ Dep Geografia - Universdade de Coimbra/Portugal \\ BENTO-GONÇALVES, Antônio José - bento@geografia.uminho.pt \\ Centro de Estudos em Geografia e Ordenamento do Território - Universidade do \\ Minho/Portugal
}

\begin{abstract}
RESUMO: Em Portugal, por razões meramente estatísticas, a Autoridade Florestal Nacional - AFN (atual Instituto de Conservação da Natureza e da Florestal - ICNF) definiu como 'grandes incêndios florestais' (GIF), aqueles cuja área ardida fosse superior a 100ha. Nos últimos 10 anos, de 2003 a 2012, foram contabilizados, no território continental português, 31 GIF com dimensão superior a 5000ha (12 deles com área superior a $10000 \mathrm{ha}$ ), tendo estes ocorrido sempre nos meses de julho a setembro. Muito embora a relação existente entre determinadas situações sinópticas e a ocorrência de GIF ser já conhecida em Portugal, tendo vários autores tentado identificar as mais favoráveis (REBELO, 1980; LOURENÇO, 1988; CUNHA e BENTO-GONÇALVES, 1994), na nova realidade dendrocaustológica, que poderá mesmo configurar a existência de um novo regime de fogo em Portugal, é fundamental identificar padrões sinópticos associados aos GIF (superiores a 5000ha), o que poderá constituir uma importante ferramenta meteorológica na gestão dos incêndios florestais.
\end{abstract}

Palavras-Chave: Grandes incêndios florestais, situações sinópticas, ferramenta de gestão.

SYNOPTIC CLIMATOLOGY OF LARGE FOREST FIRES IN (> 5.000 HA) MAINLAND PORTUGAL

ABSTRACT: In Portugal, for purely statistical reasons, the National Forestry Authority NFA (now Institute for Nature and Forestry Conservation - INFC) defined as 'large forest fires' (LFF), those that burnt an area greater than 100ha. Over the past 10 years, from 2003 to 2012, were accounted, for Portuguese mainland territory, 31 LFF larger than 5000 ha (12 of them with an area exceeding 10000ha), and these always occurred in the months from July to September. Although the relationship between certain synoptic situations and the occurrence of LFF is already known in Portugal, several authors tried to identify the most favorable (F. Rebelo, 1980; L. Lourenço, 1988; L. Cunha e A. BentoGonçalves, 1994), in the new reality of fire, that can even configure the existence of a new fire regime in Portugal, it is essential to identify synoptic patterns associated with LFF (5000ha above), which could be an important meteorological tool in the management of wildfires.

Keywords: Large forest fires, synoptic type, management tool. 


\section{INTRODUÇÃO}

Os grandes incêndios florestais, a nível mundial, sempre existiram, mesmo em locais climaticamente menos propensos à sua ocorrência, como sejam o Alasca, o Canadá ou a Sibéria (REBELO, 1996) e são um problema recorrente em alguns países, como por exemplo na Austrália ou nos EUA. No entanto, apesar de se tratar de um problema global, quer pela repartição espacial quer pela sua evolução temporal, não existe na literatura nacional ou internacional uma definição universal de 'grande incêndio florestal' (GIF), sendo que esta varia normalmente de país para país (VIEGAS, 1998). Aliás, vários são os critérios encontrados na literatura utilizados para definir um GIF, mas o mais comumente utilizado é considerar-se classes de dimensão do fogo em termos da sua área ardida. Na Europa, os incêndios superiores a 100ha (BERMUDEZ et al., 2009), 500ha (MORENO et al., 1998) ou 1.000ha (PIÑOL et al., 1998; VIEGAS, 1998) são geralmente considerados GIF. Em Portugal, por razões meramente estatísticas, a ex- AFN, atual ICNF, define como GIF os incêndios cuja área ardida seja superior a $100 \mathrm{ha}^{1}$.

Mas, se em termos estatísticos o critério da dimensão é importante, em termos operacionais, ambientais ou humanos, a duração, a extensão (quando superior à média da região onde ocorre), a intensidade do incêndio (que pode impedir o seu controlo), a severidade (que pode provocar importantes danos ambientais), o local onde ocorre (que pode colocar vidas e bens em perigo - interfaces urbanorurais), os meios envolvidos, o número de vítimas mortais, os prejuízos ou ainda a velocidade de propagação das chamas, entre outros, parecem-nos ser elementos fundamentais a ter em conta numa definição de GIF.

Independentemente das questões levantadas acima e sobre as quais deve recair alguma atenção mas que se consideram secundárias neste trabalho, a verdade, porém, é que os excecionais registos de incêndios dos últimos anos, por exemplo 1978/79 e 1994 em Espanha; 1998, 2000 e 2007, na Grécia; 2003 e 2005, em Portugal e 2003 um pouco por toda a Europa, ajudaram a realçar a importância dos GIF (entendidos como incêndios de grandes dimensões em termos da sua área ardida) no Sul da Europa Mediterrânea (OLIVERAS et al., 2009; PIÑOL et al., 1998; PAUSAS, 2004; XANTHOPOULOS, 2007).

A compreensão dos fatores que regem a incidência e a propagação de GIF é, portanto, imprescindível para apoiar o planeamento eficaz de mitigação e combate a incêndios (CUNHA e BENTO-GONÇALVES, 1994). A incidência e o tamanho dos incêndios são naturalmente influenciados por uma série de fatores, dos quais queremos destacar, em particular neste trabalho, as situações sinópticas que poderão estar associadas á ocorrência dos GIF de maiores dimensões (com área ardida superior a 5000ha) ocorridos na última década (2003-2012).

Os regimes pluviométricos de carácter mediterrâneo, em que se conjugam condições estivais, mais ou menos longas, de elevadas temperaturas com escassez de precipitação, correspondem às condições necessárias (mas não

\footnotetext{
${ }^{1} \mathrm{Na}$ década de 70 do século passado a então Direção Geral das Florestas considerava como GIF os incêndios cuja área ardida fosse superior a 10ha (L. Cunha e A. Bento-Gonçalves, 1994).
} 
suficientes) para a eclosão e propagação de incêndios florestais que, frequentemente, e em função da sua duração e extensão da área ardida, se constituem como grandes incêndios florestais (GIF). Em Portugal Continental, entre os anos de 2003 e 2012, inventariaram-se 31 incêndios com estas características, todos eles ocorridos em 82 dias dos meses de Julho, Agosto e Setembro, precisamente aqueles em que, normalmente, ocorrem os tipos de tempo mais favoráveis à eclosão e propagação do fogo. Embora normalmente, durante o Verão, na fachada atlântica da Península Ibérica, as condições atmosféricas sejam quase sempre favoráveis à deflagração de fogos florestais, à exceção de alguns (poucos) dias em que ocorre precipitação, períodos há em que tais condições são particularmente propícias, mais do que nos restantes dias. Subjacente a esta variabilidade interdiurna, intraestival e interestival, está toda uma diversidade de tipos de tempo (GANHO, 1991), imposta por uma diversidade de condições sinópticas suprajacentes a variações interdiurnas da dinâmica atmosférica regional, especialmente na baixa troposfera, e na sua interação com fatores geográficos intervenientes às escalas regional e local do território de Portugal Continental. Entre estes tipos de tempo estão os que determinam maior risco de incêndio florestal, que correspondem a períodos de temperaturas mais elevadas conjugadas com baixos valores de humidade relativa, restringidos às regiões do interior, ou generalizando-se a todo o território, inclusive ao litoral ocidental, onde são menos frequentes, mas onde o vento é, quase sempre, mais forte e persistente. Tudo na dependência da fisionomia do campo de pressão e da direção e velocidade dos fluxos à superfície, do estado termodinâmico vertical da troposfera e dos movimentos verticais do ar, e da origem, trajeto e características das massas de ar que invadem o território.

São as condições sinópticas que vigoraram durante os períodos em que ocorreram os GIF inventariados no período em análise que se analisam, classificam e caracterizam, do ponto de vista da dinâmica atmosférica regional, das suas consequências climático-meteorológicas e da frequência de ocorrência, com o objetivo fundamental de aplicação à prevenção dos riscos dendrocaustológicos.

\section{MATERIAL E METODOLOGIA}

\section{$\underline{\text { Antecedentes }}$}

Em Portugal não são conhecidos muitos documentos escritos relativos a grandes incêndios florestais anteriores ao séc. XX, mas podemos destacar alguns dos relatos existentes: Silva e Batalha (1859) referem que a região da Mata Nacional de Leiria foi afetada por diversos fogos entre 1806 e 1824, o último dos quais terá sido de grandes proporções (5000ha); também PINTO, na sua obra "O Pinhal do Rei" (1939), relata que um incêndio florestal em 1824 consumiu cerca de 5000ha na referida Mata Nacional de Leiria; ainda no séc. XIX, em 18821883, terá ocorrido um incêndio de grandes proporções na "Matta do Bussaco", referido por NAVARRO (1884) no seu livro "Quatro dias na serra da Estrela".

Embora não existam referências diretas a incêndios florestais durante as Invasões Francesas (1807-1814), a política de "terra queimada" praticada à 
época, terá implicado a existência de inúmeros incêndios, alguns dos quais terão assumido grandes dimensões.

Mais recentemente, nos anos 60 do séc. XX, depois do GIF de Vale do Rio (Leiria, Figueiró dos Vinhos) em 1961 (LOURENÇO, 2009), o Plano Nacional de Defesa da Floresta contra Incêndios (APIF, 2005) refere a ocorrência de três GIF: em Viana do Castelo (1962), em Boticas (1964) e em Sintra (1996). Se o sinistro de Sintra (6-12 de Setembro de 1966) que consumiu cerca de 5000ha está bem documentado, visto ter ceifado a vida a 25 militares, os outros dois nunca foram convenientemente estudados, havendo apenas a registar a referência que Quintanilha, Silva e Moreira da Silva (1965) fazem ao incêndio de Viana do Castelo: "A partir de 1960, nos Perímetros Florestais, o valor dos prejuízos processou-se num ritmo alarmante $(2.500,4.000$ e 9.500 contos naquele ano e nos dois seguintes) e só em 1962, num incêndio, se perderam, apesar de todos os esforços, quase 5000ha de pinhal e sentiu-se a inoperância do ataque logo que o sinistro atingisse determinadas proporções".

Apesar destes relatos, até à década de 70 do século passado, os incêndios não eram considerados um problema-chave para a floresta portuguesa. A partir desta data, verificou-se um aumento da acumulação de combustível nas florestas, devido à redução do pastoreio e à falta da roça de matos para a cama dos gados, provocadas pelo êxodo rural iniciado por volta dos anos 50, que refletia de perto as mudanças socioeconómicas então em curso nos países do sul da Europa, em particular nas regiões do Mediterrâneo (LOURENÇP, 1991; VÉLEZ, 1993; MORENO et al., 1998; REGO, 2001). Estas mudanças no uso tradicional da terra e estilo de vida das populações implicaram o aumento de grandes áreas abandonadas de anteriores terras agrícolas, o que, por um lado, levou à recuperação da vegetação e ao aumento do combustível acumulado nos espaços florestais tradicionais (LOURENÇO, 1991; Rego, 1992; GARCÍA-RUIZ et al., 1996; M. J. ROXO et al., 1996) e, por outra parte, conduziu, naturalmente, ao aumento dos espaços com uso florestal. Áreas de agricultura marginal produtiva foram convertidas em plantações florestais ou abandonadas ao processo natural de sucessão ecológica e, assim, convertido em matos e florestas, tal como acontecia em outras regiões do sul da Europa (PAUSAS, 1999; MORENO, 1999; LLORET et al., 2002; MOUILLOT et al., 2003). Muitas destas áreas rurais tornaram-se paisagens propensas à ocorrência de incêndios de grande intensidade, devido aos elevados níveis de biomassa, acumulados ao longo dos anos e prontos para alimentar fogos catastróficos durante o Verão.

Assim, começaram a "vulgarizar-se" os incêndios florestais com área igual ou superior a 100ha e, apesar de até à década de 80 do século passado, os incêndios no nosso país nunca terem atingido 10.000ha de área ardida numa só ocorrência, depois de ter ocorrido o primeiro, em 1986, no concelho de Vila de Rei (LOURENÇO, 1986), podemos dizer que se deu início a uma nova realidade no que respeita aos grandes incêndios. 


\section{Dados}

Numa tentativa de apurarmos a importância dos GIF no âmbito dos incêndios florestais e da área ardida totais, verificamos que estes, desde há 3 décadas, detêm uma importância significativa, sobretudo no que concerne à área florestal (mato e povoamentos) que queimam.

Com base nas estatísticas dos incêndios disponibilizadas pelo ICNF (2012), observa-se que no decénio 1983-1992 os GIF representaram 1,3\% do total das ocorrências de incêndios florestais (superiores a 1ha) registadas nesses 10 anos, sendo este o valor mais significativo das últimas 3 décadas ( $0,6 \%$ em $1993-$ 2002 e 0,7\% em 2003-2012) (Tabela 1). Muito embora, no que respeita à área ardida, esta não tenha sido a década mais representativa pesem embora os $71,4 \%$ de área ardida por GIF contra 63,3\% registados entre 1993 e 2002 e os $79,3 \%$ da última década, constituindo este último, o valor mais significativo das últimas três décadas. Emerge assim um aspeto que importa assinalar, o facto de nos últimos dez anos se terem registado os grandes incêndios florestais de maior dimensões, isto porque, apesar de não se ter registado entre 2003 e 2012 a maior percentagem de ocorrências de GIF registou-se a maior área ardida, o que significa que cada ocorrência observada nesta década queimou mais do que as registadas nas anteriores. Isto representa portanto, que embora o número dos grandes incêndios florestais não tenha vindo a aumentar ao longo dos anos, tem-se registado um aumento dos maiores "grandes incêndios".

\begin{tabular}{|c|c|c|c|c|c|c|}
\hline & $\begin{array}{c}\text { Ocorrências } \\
\left(n^{\circ}\right)\end{array}$ & $\begin{array}{c}\text { Área } \\
\text { ardida (ha) }\end{array}$ & $\begin{array}{l}\text { Ocorrência } \\
\text { s GIF }\left(n^{\circ}\right)\end{array}$ & $\begin{array}{l}\text { Ocorrências } \\
\text { GIF (\%) }\end{array}$ & $\begin{array}{l}\text { Área ardida } \\
\text { GIF (ha) }\end{array}$ & $\begin{array}{l}\text { Área ardida } \\
\text { GIF (\%) }\end{array}$ \\
\hline $\begin{array}{c}\text { Década } \\
1983-1992\end{array}$ & 101130 & 937985 & 1348 & 1,3 & 669741 & 71,4 \\
\hline $\begin{array}{c}\text { Década } \\
1993-2002\end{array}$ & 275300 & 1041649 & 1729 & 0,6 & 658968 & 63,3 \\
\hline $\begin{array}{c}\text { Década } \\
2003-2012\end{array}$ & 241823 & 1416027 & 1598 & 0,7 & 1122878 & 79,3 \\
\hline
\end{tabular}

Tabela 1 - Ocorrências e área ardida de incêndios florestais e dos grandes incêndios florestais em Portugal continental, por decénios Fonte: ICNF, 2012

Pelo referido acima propusemo-nos analisar as particularidades das ocorrências e respetivas áreas ardidas dos grandes incêndios florestais da última década. Com base na mesma fonte (ICNF) verificamos que no conjunto dos últimos dez anos, 2003 foi aquele que registou a maior área ardida, com os grandes incêndios florestais a serem responsáveis por mais de 395640ha, 92\% do total da área ardida, embora representassem menos de $1 \%$ das ocorrências (253 ocorrências). Já o ano de 2005 foi aquele em que mais ocorrências de GIF foram registadas embora com uma área ardida inferior ao ano de 2003, mas mesmo assim muito significativa, representando $85 \%$ do total das áreas ardidas nesse ano (num total de $287668 \mathrm{ha}$ ). Estes constituem de facto os anos mais 
ISSN: 1980-055x (Impressa) 2237-8642 (Eletrônica)

preocupantes em termos da ocorrência de grandes incêndios e da sua área ardida (figura 1). Para os valores máximos atingidos nestes dois anos, de áreas ardidas no caso de 2003, e número de ocorrências em 2005, muito contribuíram as condições climáticas, que se apresentaram bastante favoráveis tanto à ignição como à propagação de incêndios nestes $\operatorname{anos}^{2}$ (LOURENÇO et al., 2012).

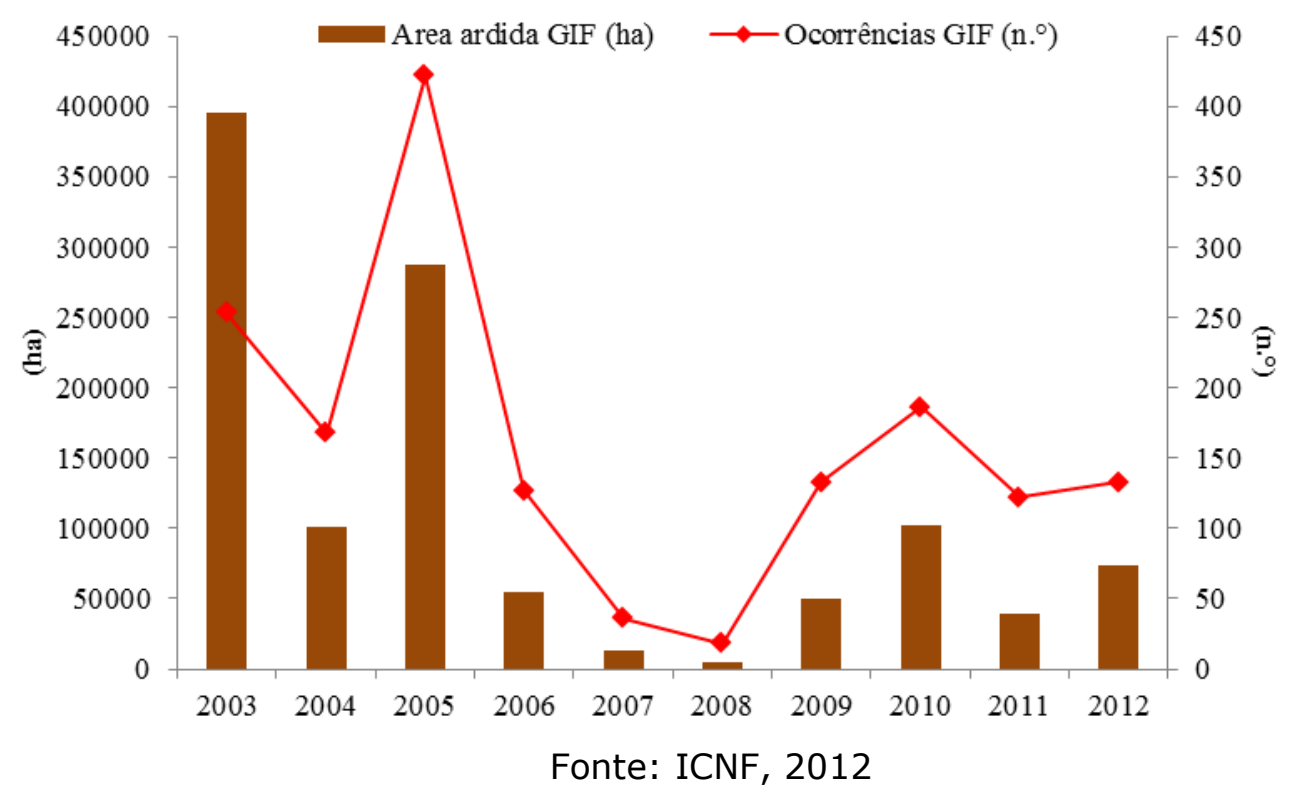

Figura 1 - Ocorrências de GIF ( $\left.n^{\circ}\right)$ e área ardida (ha) por GIF, por ano, entre 2003 e 2012, em Portugal Continental

Por outro lado, os anos de 2007 e 2008 foram aqueles que registaram menos GIF, relativamente ao número total de ocorrências, 0,2\% (36 ocorrências) e $0,1 \%$ (18 ocorrências), respetivamente, acompanhados de uma menor área ardida, 42,6\%, correspondentes a 13615ha, e 25,9\% (4339ha). A partir de 2008, incrementa-se novamente tanto o número de ocorrências como as áreas ardidas por GIF, sem se ultrapassar contudo, os valores atingidos nos anos de 2003 e 2005.

Desagregando a informação relativa aos grandes incêndios na última década verifica-se que as ocorrências mais frequentes foram as que queimaram áreas entre os 100 e os 500ha, representando um pouco mais de $71 \%$ do total das ocorrências de GIF, tendo estas sido responsáveis por 22,3\% da totalidade das áreas ardidas por GIF neste período. Os de maiores dimensões, como aqueles com área superior a 5.000ha, representaram 1,9\% do total das ocorrências e queimaram $27 \%$ da área total ardida por GIF (Tabela 2), confirmando que de facto, em termos gerais, os GIF representam uma pequena fração do número

\footnotetext{
2 Os GIF estão dependentes de uma série de fatores e constrangimentos que não interessa aqui enumerar. Mas, se as condições climáticas são um dos condicionalismos importantes para a presença de GIF, sendo este o aspeto que queremos realçar neste trabalho, não podemos deixar de referir a importância da gestão dos espaços florestais. A distribuição espacial dos GIF pode constituir um instrumento essencial para a identificação das principais áreas a intervir (L. Lourenço et al., 2012)
} 
total de incêndios mas são responsáveis por uma grande percentagem da área total ardida

\begin{tabular}{|c|c|c|c|c|c|c|c|c|c|c|c|c|}
\hline & $\begin{array}{c}{[100-} \\
500[ \\
\text { ha } \\
(\%)\end{array}$ & $\begin{array}{c}{[100-} \\
500[ \\
\text { ha } \\
(\%)\end{array}$ & $\begin{array}{c}{[500-} \\
1000[ \\
\text { ha } \\
(\%)\end{array}$ & $\begin{array}{c}{[500-} \\
1000[ \\
\text { ha } \\
(\%)\end{array}$ & $\begin{array}{c}\text { [1000- } \\
5000[ \\
\text { ha } \\
(\%)\end{array}$ & $\begin{array}{c}\text { [1000- } \\
5000[ \\
\text { ha } \\
(\%)\end{array}$ & $\begin{array}{c}\text { [5000- } \\
10000[ \\
\text { ha } \\
(\%)\end{array}$ & $\begin{array}{c}\text { [5000- } \\
10000[ \\
\text { ha } \\
(\%)\end{array}$ & $\begin{array}{c}\text { [10000- } \\
20000[ \\
\text { ha } \\
(\%)\end{array}$ & $\begin{array}{c}\text { [10000- } \\
20000[ \\
\text { ha } \\
(\%)\end{array}$ & $\begin{array}{c}>20000 \\
\text { ha } \\
(\%)\end{array}$ & $\begin{array}{c}>20000 \\
\text { ha } \\
(\%)\end{array}$ \\
\hline 2003 & 53,4 & 7,7 & 14,6 & 6,7 & 24,5 & 36,0 & 4,0 & 18,0 & 3,2 & 25,9 & 0,4 & 5,5 \\
\hline 2004 & 68,5 & 24,6 & 17,3 & 20,1 & 13,1 & 34,8 & 0,6 & 7,9 & 0,6 & 12,6 & 0,0 & 0,0 \\
\hline 2005 & 67,5 & 23,4 & 18,0 & 18,5 & 13,0 & 41,8 & 1,2 & 12,2 & 0,2 & 4,1 & 0,0 & 0,0 \\
\hline 2006 & 80,3 & 41,7 & 14,2 & 23,6 & 4,7 & 24,5 & 0,8 & 10,2 & 0,0 & 0,0 & 0,0 & 0,0 \\
\hline 2007 & 83,3 & 44,8 & 11,1 & 21,2 & 5,6 & 34,0 & 0,0 & 0,0 & 0,0 & 0,0 & 0,0 & 0,0 \\
\hline 2008 & 88,9 & 73,4 & 11,1 & 26,6 & 0,0 & 0,0 & 0,0 & 0,0 & 0,0 & 0,0 & 0,0 & 0,0 \\
\hline 2009 & 82,7 & 44,3 & 10,5 & 20,1 & 6,0 & 21,6 & 0,8 & 14,0 & 0,0 & 0,0 & 0,0 & 0,0 \\
\hline 2010 & 72,6 & 28,1 & 14,0 & 18,0 & 12,9 & 48,9 & 0,5 & 5,0 & 0,0 & 0,0 & 0,0 & 0,0 \\
\hline 2011 & 83,6 & 54,4 & 11,5 & 23,5 & 4,9 & 22,1 & 0,0 & 0,0 & 0,0 & 0,0 & 0,0 & 0,0 \\
\hline 2012 & 81,2 & 31,4 & 11,3 & 14,9 & 6,8 & 24,7 & 0,0 & 0,0 & 0,0 & 0,0 & 0,8 & 29,0 \\
\hline Média & 71,2 & 22,3 & 14,7 & 14,8 & 12,1 & 36,0 & 1,2 & 11,8 & 0,6 & 11,3 & 0,1 & 3,9 \\
\hline
\end{tabular}

Tabela 2 - Evolução do número de ocorrências e das áreas ardidas de grandes incêndios florestais, por classes de dimensão, em percentagem

Fonte: ICNF, 2012

No contexto dos GIF propusemo-nos igualmente analisar com maior pormenor as maiores ocorrências de GIF, ou seja, aquelas com área ardida superior a 5000 ha. Do conjunto total destas ocorrências destaca-se o ano de 2003, com 19 das 31 ocorrências registadas, seguido do ano de 2005 com 6 ocorrências com área ardida superior a 5000ha, seguindo-se o ano de 2004 com 2 ocorrências. Os anos de 2006, 2009 e 2010 registaram uma ocorrência, individualmente (Tabela 3).

\begin{tabular}{|c|c|c|c|c|c|}
\hline Ano & Distrito & Concelho & Freguesia & $\begin{array}{l}\text { Data } \\
\text { alerta }\end{array}$ & $\begin{array}{c}\text { Área ardida } \\
\text { (ha) }\end{array}$ \\
\hline 2003 & Faro & Monchique & Alferce & 2003-09-11 & 16008 \\
\hline 2003 & Faro & Silves & Silves & $2003-08-12$ & 11703 \\
\hline 2003 & Faro & Monchique & Marmelete & $2003-08-08$ & 12342 \\
\hline 2003 & Portalegre & Nisa & São Matias & $2003-07-30$ & 14400 \\
\hline 2003 & Portalegre & Gavião & Belver & 2003-08-01 & 14412 \\
\hline 2003 & Portalegre & Nisa & Montalvão & $2003-07-31$ & 8279 \\
\hline 2003 & Portalegre & Castelo de Vide & São João Baptista & $2003-07-31$ & 8700 \\
\hline 2003 & Beja & Odemira & Saboia & 2003-09-12 & 9317 \\
\hline 2003 & Castelo Branco & Vila Velha de Ródão & Vila Velha de Ródão & 2003-08-03 & 5000 \\
\hline 2003 & Castelo Branco & Oleiros & Orvalho & 2003-07-29 & 9018 \\
\hline 2003 & Castelo Branco & Oleiros & Isna & 2003-08-01 & 10800 \\
\hline 2003 & Castelo Branco & Vila de Rei & Fundada & $2003-07-30$ & 8720 \\
\hline 2003 & Castelo Branco & Sertã & Ermida & 2003-08-02 & 10021 \\
\hline 2003 & Castelo Branco & Castelo Branco & Almaceda & $2003-07-28$ & 5110 \\
\hline 2003 & Castelo Branco & Proença-a-Nova & Sobreira Formosa & 2003-08-01 & 12920 \\
\hline 2003 & Castelo Branco & Idanha-a-Nova & Proença-a-Velha & 2003-08-14 & 5728 \\
\hline 2003 & Santarém & Mação & Envendos & 2003-08-03 & 5627 \\
\hline 2003 & Santarém & Abrantes & São Miguel do Rio Torto & 2003-08-02 & 5900 \\
\hline 2003 & Santarém & Chamusca & Ulme & 2003-08-02 & 21897 \\
\hline
\end{tabular}


Revista Brasileira de Climatologia

ISSN: 1980-055x (Impressa) 2237-8642 (Eletrônica)

\begin{tabular}{|lccccc|}
\hline 2004 & Faro & Loulé & Alte & $2004-07-26$ & 12807 \\
\hline 2004 & Beja & Almodôvar & São Barnabé & $2004-07-26$ & 8000 \\
\hline 2005 & Guarda & Seia & Vide & $2005-07-19$ & 7051 \\
\hline 2005 & Coimbra & Pampilhosa da Serra & Vidual & $2005-08-13$ & 11707 \\
\hline 2005 & Aveiro & Arouca & Janarde & $2005-08-03$ & 8556 \\
\hline 2005 & Santarém & Ourém & Urqueira & $2005-08-04$ & 5650 \\
\hline 2005 & Santarém & Abrantes & Fontes & $2005-08-20$ & 6694 \\
\hline 2005 & Vila Real & Vila Pouca de Aguiar & Parada de Monteiros & $2005-08-07$ & 7086 \\
\hline 2006 & Viana do Castelo & Arcos de Valdevez & Carralcova & $2006-08-06$ & 5590 \\
\hline 2009 & Guarda & Sabugal & Sortelha & $2009-08-30$ & 7080 \\
\hline 2010 & Viseu & São Pedro do Sul & São Cristovão De Lafões & $2010-08-06$ & 5066 \\
\hline 2012 & Faro & Tavira & Cachopo & $2012-07-18$ & 24843 \\
\hline
\end{tabular}

Tabela 3 - Ocorrências e área ardida de GIF, de dimensão igual ou superior a 5000ha, entre 2003 e 2012

Fonte: ICNF, 2012

Foram efetivamente, o ano de 2012 e o de 2003, que registaram as duas maiores áreas ardidas num só incêndio. O máximo de área ardida registado, 24843 ha, concelho de Tavira, Faro, data do dia 18 de Julho de 2012, e 21897 ha atingidos no distrito de Santarém, concelho de Chamusca, no dia 2 de Agosto de 2003.

Em termos da sua distribuição espacial, destacam-se os GIF ocorridos nos distritos de Castelo Branco, com 8 ocorrências na última década, Faro e Santarém, com 5 ocorrências cada e Portalegre com 4 ocorrências (figura 2).

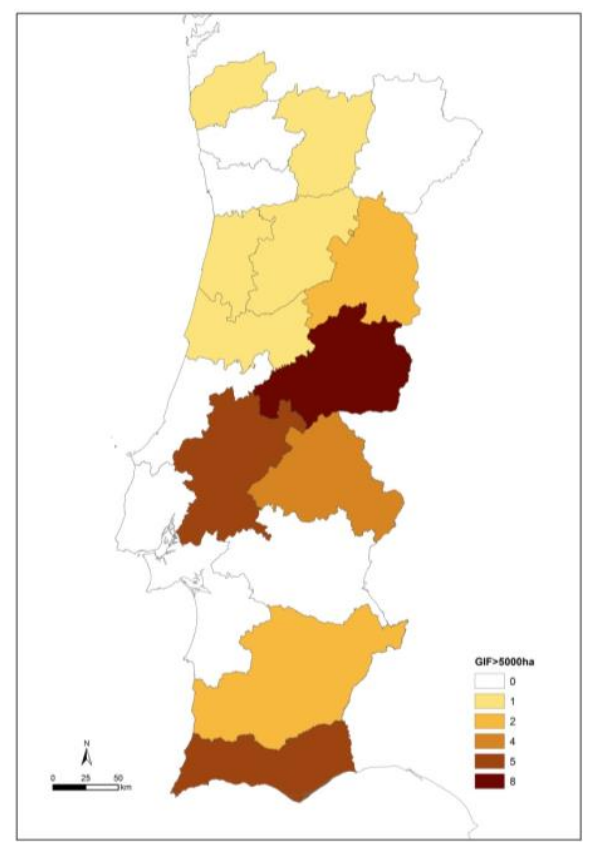

Figura 2 - Ocorrências de GIF $\left(n .^{\circ}\right)$, de dimensão igual ou superior a 5000 ha, por distrito, entre 2003 e 2012, em Portugal Continental.

Fonte: ICNF, 2012

\section{Metodologia}


No período estival, nos níveis médios e altos da troposfera, a par do enchimento e contração latitudinal do vórtice circumpolar, a cintura das altas pressões subtropicais desloca-se para latitudes mais elevadas, mergulhando as regiões subtropicais, especialmente as das fachadas ocidentais dos continentes e orientais dos oceanos, nos fluxos subsidentes que a caracterizam. Estas condições de abrigo aerológico, em circulação zonal (Abz), ou em circulação meridiana (Abm) em crista de eixo ibérico ou em gota-quente, dificultam a penetração de perturbações da frente polar (Pfp) ou de perturbações de gota-fria (Pgf) geradoras de convecção suficientemente espessa para originar episódios de precipitação significativa nestas regiões subtropicais, onde se enquadra a Península Ibérica e, naturalmente, o território de Portugal Continental. Nesta altura do ano, as perturbações frontais que, pontualmente, varrem o país, fazem-no em situação de margem anticiclónica, inibidora das ascendências, e a instabilidade determinada por eventuais perturbações de gota-fria é mitigada pela rápida tropicalização do ar polar a todos os níveis da troposfera.

A continuidade zonal das altas pressões subtropicais em altitude é substituída, na baixa troposfera, por células anticiclónicas, de carácter dinâmico, quentes ou mistas quando no seu flanco oriental é injetado ar polar, classificadas, no caso concreto do espaço que abrange o Atlântico Oriental, a Europa e o Mediterrâneo, em função da localização do seu núcleo, da sua fisionomia e da sua estrutura interna, em distintos tipos de anticiclones (RAMOS, 1986 e 1987; GANHO, 1991), na dependência direta do regime de circulação do fluxo circumpolar dos níveis médios a altos da troposfera, nas latitudes médias. A referida classificação dos anticiclones, atlânticos ou europeus, distingue os seguintes: anticiclone atlântico subtropical (As) - comummente conhecido por anticiclone dos Açores -, anticiclone atlântico misto ( $\mathrm{Aa}$ ), anticiclone atlântico misto com apófise polar (Ap), anticiclone atlântico misto estendendo-se pela Europa Ocidental (Ao), ou anticiclone europeu $(\mathrm{Ae})$. Contempla ainda mais três anticiclones, nomeadamente: anticiclone atlântico misto ligado ao anticiclone térmico europeu (At), que não foi aqui considerado pelo facto de, durante o Verão, não existir o anticiclone térmico europeu, e os anticiclones ibero-mediterrâneo (Am) e iberoafricano $(\mathrm{Ai})$, ambos centrados sobre a Península Ibérica mas de aparecimento muito raro no Verão, pelo facto de nesta época do ano o interior ibérico inibir a manifestação de anticiclogénese de superfície.

As características da anticiclogénese e a dinâmica espácio-temporal da fisionomia dos anticiclones que influenciam a fachada atlântica da Península Ibérica condicionam a circulação regional na baixa troposfera, determinando a direção e velocidade dos fluxos e as características das massas de ar que invadem o território, constituindo, por isso, um dos fatores fundamentais para a compreensão dos tipos de tempo estivais e da sua sucessão habitual. Mas só quando considerados na sua interação com a deformação ibérica do campo de pressão à superfície, de origem térmica.

Com efeito, o forte aquecimento do ar pela base nos meses estivais sobre a Península Ibérica e os acentuados contrastes térmicos de superfície entre esta massa terrestre e o Atlântico adjacente gera campos de pressão de origem térmica, de carácter quase permanente, restringidos aos níveis mais baixos da troposfera e a que se sobrepõem, normalmente acima do geopotencial a $850 \mathrm{hPa}$, as altas pressões subtropicais. Este campo de pressão pelicular manifesta-se, ou como uma depressão ibérica fechada (Bif), cuja pressão não desce aquém dos 
1010hPa, ou como uma deformação em vale (Biv), abrangendo toda a Península Ibérica, do flanco SE ou Sul das células anticiclónicas que influenciam esta região. Os fluxos sinópticos de superfície e o tipo e características das massas de ar que são canalizadas para Portugal Continental, dependem muito da posição do centro da baixa térmica fechada ou do eixo do vale térmico em relação ao território português e da circulação conjunta com as células anticiclónicas com que interagem. Quando o centro depressionário ou o eixo do vale se posicionam mais para o interior da Península Ibérica - em Espanha (esp) ou no interior português (int) - os gradientes barométricos W-E sobre Portugal fomentam fluxos, à superfície, de NW ou N, especialmente no litoral ocidental, constituindo o sistema de "nortada". A nortada é habitualmente mais forte e persistente quando o campo depressionário ibérico interage com os anticiclones $\mathrm{Aa}$ ou Ap, uma vez que a intrusão de ar polar nestes anticiclones intensifica os gradientes barométricos na fachada atlântica da Península Ibérica, mas também se faz sentir com a influência do anticiclone As, ou dos anticiclones Ao e Ae. Nestas condições ocorre a advecção de massas de ar Polar marítima direta (Pmd) ou tropicalizada (Pmt) quando dominam os anticiclones Ap e $\mathrm{Aa}$, ou Polar continental direta (Pcd) ou tropicalizada (Pct), transportadas na circulação conjunta da baixa térmica ibérica com os anticiclones $A o$ ou $A e$, ou ainda Tropical marítima direta (Tmd) ou continentalizada (Tmc), canalizadas pela interação entre a baixa térmica ibérica e o anticiclone As, no primeiro caso com a crista desenvolvida diretamente para a Península Ibérica, no segundo caso com a expansão da crista por sobre o Golfo da Biscaia, França e Península Ibérica. Em qualquer uma destas situações, quando o gradiente barométrico de superfície sobre Portugal é mais débil, o arrefecimento pela base das massas de ar em contacto com o Atlântico adjacente, superficialmente arrefecido pelo mecanismo de upwelling oeste ibérico (FERREIRA, 1984) induzido pelo sistema de nortada, dá origem a uma massa de ar marítimo, de carácter pelicular, fresca e muito húmida (Amp), que invade as regiões do litoral Norte e Centro do país, especialmente durante a madrugada e manhã, com penetração continental limitada e variável em função da topografia, responsável, nas áreas invadidas, por temperaturas mais baixas e humidade relativa mais elevada do que no resto do território, para além de nebulosidade baixa e nevoeiros de advecção, de dissipação matinal.

As condições de tempo mais quente e de maior secura do ar, generalizadas a todo o território de Portugal Continental, inclusive ao litoral Oeste, e que, quando intensas e persistentes constituem "ondas de calor", ocorrem quando, ou o centro da baixa térmica fechada, ou o eixo da baixa térmica em vale, migram para o litoral Oeste (lit), ou ainda, quando o vale térmico ibérico se agrega ao campo depressionário de origem térmica do Noroeste de África, constituindo-se como uma baixa térmica ibero-africana (Bia), muitas vezes com um centro depressionário fechado no seu interior, posicionado no Sul, ou a Sul do território (naf). Este tipo de fisionomia do campo térmico ibérico ou ibero-africano inserese, normalmente, no flanco Sul do anticiclone As, muito distendido para o mediterrâneo ocidental e Norte de África, ou no flanco Sul do anticiclone Ae ou mesmo do anticiclone Ao. Portugal Continental fica, assim, diretamente sob influência da circulação do flanco oriental do vale térmico ou da baixa térmica fechada, com fluxos de NE, E, ou SE, atenuando ou anulando o sistema de nortada, fomentando a invasão de massas de ar, ou Tropical continental ibérica (Tci), ou, quando a percurso sobre o Noroeste africano é suficientemente longo, Tropical continental africana (Tca), as mais quentes e secas que afluem à 
fachada atlântica da Península Ibérica e a que, por isso, estão associados os mais elevados riscos de ocorrência de GIF. A mitigação ou desaparecimento destas condições de elevado risco dendrocaustológico ocorre com a substituição da influência direta das massas de ar tropical com trajeto continental por invasão de ar marítimo no litoral, ou de massas de ar com origem polar, recente ou tropicalizado, influenciando todo o território. O que implica a deslocação para Leste, ou do eixo do vale térmico ibérico ou ibero-africano, ou do centro da baixa térmica fechada, com reconstituição do sistema de nortada e interrupção do fluxo direto do Norte de África nos níveis baixos da troposfera. As causas sinópticas desta modificação do padrão do campo de pressão de superfície associado às ondas de calor, e que ocorre em fase com condições de abrigo aerológico zonal ( $A b z$ ) ou em crista $(A b c)$ em altitude, é a invasão dos níveis médios e altos da troposfera ibérica por advecção polar fria, em vale (Afv) ou em gota (Afg). Quando esta advecção polar em altitude se sobrepõe à baixa térmica ibérica, esta transforma-se em baixa ibérica mista (Bim), acentua-se o gradiente térmico vertical e geram-se condições de instabilidade, favoráveis ao aparecimento de células nebulosas de desenvolvimento vertical e de precipitação, sob a forma de aguaceiros, por vezes fortes, de chuva ou de granizo, e de trovoadas dispersas, com particular incidência nas regiões do interior, que no Verão não perduram senão por muito curtos períodos de tempo, mas que concorrem para a extinção de incêndios florestais.

Na Tabela 4 sintetizam-se e classificam-se, então, as situações sinópticas que caracterizam, normalmente, a dinâmica atmosférica na Europa, Atlântico Norte Oriental e Mediterrâneo Ocidental, no período estival, e que estão na base da diversidade de tipos de tempo de Verão em Portugal Continental e na explicação das condições, mais ou menos favoráveis aos incêndios florestais nesta época do ano.

\begin{tabular}{|c|c|}
\hline \multicolumn{2}{|l|}{ ALTITUDE (500hPa) } \\
\hline $\begin{array}{l}\text { Abz: Abrigo aerológico em circulação zonal } \\
\text { Abm : Abrigo aerológico em circulação } \\
\text { meridiana (crista ou em gota-quente) }\end{array}$ & $\begin{array}{l}\text { Afv: Advecção fria em vale } \\
\text { Afg: Advecção fria em gota }\end{array}$ \\
\hline \multicolumn{2}{|l|}{ SUPERFÍCIE (nmm) } \\
\hline \multicolumn{2}{|l|}{$\begin{array}{l}\text { Perturbação } \\
\text { Pfp - Perturbação frontal polar } \\
\text { Pgf - Perturbação de gota-fria } \\
\end{array}$} \\
\hline $\begin{array}{l}\text { Anticiclone } \\
\text { As - Anticiclone atlântico subtropical } \\
\text { (anticiclone dos Açores) } \\
\text { Aa - Anticiclone atlântico misto } \\
\text { Ap - Anticiclone atlântico misto com } \\
\text { apófise polar } \\
\text { Ao - Anticiclone atlântico misto }\end{array}$ & $\begin{array}{l}\text { Baixa térmica } \\
\text { Bif - Baixa térmica ibérica fechada } \\
\text { Biv - Baixa térmica ibérica em vale } \\
\text { Bia - Baixa térmica ibero-africana } \\
\text { Bim - Baixa ibérica mista (fechada ou } \\
\text { em vale, sobreposta por advecção fria } \\
\text { em vale ou em gota) }\end{array}$ \\
\hline $\begin{array}{l}\text { Ae - Anticiclone europeu } \\
\mathbf{A m} \text { - Anticiclone ibero-mediterrâneo } \\
\mathbf{A i} \text { - Anticiclone ibero-africano }\end{array}$ & $\begin{array}{l}\text { Posição do núcleo da baixa térmica } \\
\text { fechada ou do eixo da baixa térmica em } \\
\text { vale em relação ao território do } \\
\text { continente } \\
\text { esp - Espanha } \\
\text { int - interior } \\
\text { lit - litoral Oeste } \\
\text { naf - Norte de África }\end{array}$ \\
\hline $\begin{array}{l}\text { Massa de ar invasora do território do } \\
\text { continente em função da sua origem e } \\
\text { trajecto }\end{array}$ & $\begin{array}{l}\text { Fluxo sinóptico } \\
\text { N - Norte } \\
\text { NW - Noroeste }\end{array}$ \\
\hline
\end{tabular}


ISSN: 1980-055x (Impressa) 2237-8642 (Eletrônica)

\begin{tabular}{|l|l|}
\hline Pmd - Polar marítima direta & W - Oeste \\
Pmt - Polar marítima tropicalizada & SW - Sudoeste \\
Pcd - Polar continental direta & S - Sul \\
Pct - Polar continental tropicalizada & SE - Sudeste \\
Tmd - Tropical marítima direta & E - Este \\
Tmc - Tropical marítima continentalizada & NE - Nordeste \\
Tci - Tropical continental ibérica & \\
Tca - Tropical continental africana & \\
Amp - Adveçaão de ar marítimo com & \\
origem no atlântico próximo, restrito aos & \\
níveis baixos da troposfera (pelicular) & \\
\hline
\end{tabular}

Tabela 4 - Classificação das situações sinópticas - 00h UTC

\section{RESULTADOS E DISCUSSÃO}

Procede-se, em seguida, à aplicação da classificação das situações sinópticas inventariadas na tabela 4, aos 82 dias dos meses de julho, agosto e setembro dos anos de 2003 a 2012, durante os quais lavraram 31 grandes incêndios florestais em Portugal Continental e à caracterização estatística, do ponto de vista da sua frequência de ocorrência no período em análise (Tabela 5).

\begin{tabular}{|c|c|c|c|c|c|c|c|c|c|c|}
\hline $\begin{array}{l}\text { Situações } \\
\text { Sinópticas }\end{array}$ & $\begin{array}{l}\text { No } \\
\text { dias }\end{array}$ & $\%$ & $\begin{array}{l}\text { Situações } \\
\text { Sinópticas }\end{array}$ & $\begin{array}{l}\text { No }^{\circ} \\
\text { dias }\end{array}$ & $\%$ & $\begin{array}{c}\text { Massa } \\
\text { de Ar ---> } \\
\text { Situações } \\
\text { Sinópticas }\end{array}$ & $\begin{array}{l}\text { Tca } \\
\text { No } \\
\text { dias }\end{array}$ & $\%$ & $\begin{array}{l}\text { Tci } \\
\text { No } \\
\text { dias }\end{array}$ & $\%$ \\
\hline $\begin{array}{l}\text { Abz } \\
\text { Abm } \\
\text { Afv } \\
\text { Afg }\end{array}$ & $\begin{array}{c}33 \\
38 \\
9 \\
2\end{array}$ & $\begin{array}{c}40,2 \\
46,3 \\
11,0 \\
2,4\end{array}$ & $\begin{array}{l}\mathbf{N} \\
\text { NW } \\
\text { W } \\
\text { SW }\end{array}$ & $\begin{array}{l}14 \\
15 \\
3 \\
3\end{array}$ & $\begin{array}{l}17,1 \\
18,3 \\
3,7 \\
3,7\end{array}$ & $\begin{array}{l}\text { Abz } \\
\text { Abm } \\
\text { Afv } \\
\text { Afg }\end{array}$ & $\begin{array}{l}13 \\
25\end{array}$ & $\begin{array}{l}24,5 \\
47,2\end{array}$ & $\begin{array}{l}8 \\
7\end{array}$ & $\begin{array}{l}15,1 \\
13,2\end{array}$ \\
\hline & & & $\begin{array}{l}\text { S } \\
\text { SE } \\
\text { E } \\
\text { NE }\end{array}$ & $\begin{array}{c}2 \\
6 \\
27 \\
12\end{array}$ & $\begin{array}{l}2,4 \\
7,3 \\
32,9 \\
14,6\end{array}$ & $\begin{array}{l}\text { As } \\
\text { Aa } \\
\text { Ap } \\
\text { Ao }\end{array}$ & $\begin{array}{c}22 \\
4 \\
3\end{array}$ & $\begin{array}{c}41,5 \\
7,6 \\
5,7\end{array}$ & $\begin{array}{c}13 \\
2\end{array}$ & $\begin{array}{c}24,4 \\
3,8\end{array}$ \\
\hline $\begin{array}{l}\text { As } \\
\text { Aa } \\
\text { Ap }\end{array}$ & $\begin{array}{c}43 \\
15 \\
3\end{array}$ & $\begin{array}{c}60,6 \\
21,1 \\
4,2\end{array}$ & $\begin{array}{l}\text { Pmd } \\
\text { Pmt } \\
\text { Pcd }\end{array}$ & $\begin{array}{l}3 \\
8 \\
0\end{array}$ & $\begin{array}{l}3,2 \\
8,5 \\
0,0\end{array}$ & $\begin{array}{c}\mathbf{A e} \\
\mathbf{A i} \\
\mathbf{A m}\end{array}$ & 9 & 17,0 & & \\
\hline $\begin{array}{l}\text { Ao } \\
\mathrm{Ae} \\
\mathrm{Ai} \\
\mathrm{Am}\end{array}$ & $\begin{array}{l}1 \\
9 \\
0 \\
0\end{array}$ & $\begin{array}{c}1,4 \\
12,7 \\
0,0 \\
0,0\end{array}$ & $\begin{array}{l}\text { Pct } \\
\text { Tmd } \\
\text { Tmc } \\
\text { Tci }\end{array}$ & $\begin{array}{c}6 \\
7 \\
4 \\
15\end{array}$ & $\begin{array}{r}6,4 \\
7,4 \\
4,3 \\
16,0\end{array}$ & $\begin{array}{l}\text { Bif } \\
\text { Biv } \\
\text { Bia } \\
\text { Bim }\end{array}$ & $\begin{array}{c}3 \\
6 \\
29\end{array}$ & $\begin{array}{c}5,7 \\
11,3 \\
54,7\end{array}$ & $\begin{array}{l}6 \\
5 \\
4\end{array}$ & $\begin{array}{c}11,3 \\
9,4 \\
7,6\end{array}$ \\
\hline & & & $\begin{array}{l}\text { Tca } \\
\text { Amp }\end{array}$ & $\begin{array}{l}38 \\
13\end{array}$ & $\begin{array}{l}40,4 \\
13,8\end{array}$ & $\begin{array}{l}\text { esp } \\
\text { int }\end{array}$ & $\begin{array}{l}1 \\
7\end{array}$ & $\begin{array}{c}1,9 \\
13,2\end{array}$ & $\begin{array}{l}5 \\
2\end{array}$ & $\begin{array}{l}9,4 \\
3,8\end{array}$ \\
\hline $\begin{array}{l}\text { Bif } \\
\text { Biv }\end{array}$ & $\begin{array}{l}17 \\
23\end{array}$ & $\begin{array}{l}21,8 \\
29,5\end{array}$ & & & & $\begin{array}{l}\text { lit } \\
\text { naf }\end{array}$ & $\begin{array}{l}14 \\
16\end{array}$ & $\begin{array}{l}26,4 \\
30,2\end{array}$ & $\begin{array}{l}6 \\
2\end{array}$ & $\begin{array}{c}11,3 \\
3,8\end{array}$ \\
\hline Bia & 34 & 43,6 & & & & $\mathbf{N}$ & 2 & 3,8 & 4 & 7,6 \\
\hline Bim & 4 & 5,1 & & & & NW & 2 & 3,8 & 2 & 3,8 \\
\hline $\begin{array}{l}\text { esp } \\
\text { int } \\
\text { lit } \\
\text { naf }\end{array}$ & $\begin{array}{l}24 \\
14 \\
21 \\
19 \\
\end{array}$ & $\begin{array}{l}30,8 \\
17,9 \\
26,9 \\
24,4 \\
\end{array}$ & & & & $\begin{array}{c}W \\
\text { SW } \\
\text { S } \\
\text { SE }\end{array}$ & $\begin{array}{l}2 \\
6\end{array}$ & $\begin{array}{c}3,8 \\
11,3\end{array}$ & & \\
\hline & & & & & & $\begin{array}{c}\text { E } \\
\text { NE }\end{array}$ & $\begin{array}{c}20 \\
6\end{array}$ & $\begin{array}{l}37,7 \\
11,3\end{array}$ & $\begin{array}{l}5 \\
4\end{array}$ & $\begin{array}{l}9,4 \\
7,6\end{array}$ \\
\hline
\end{tabular}

Tabela 5 - Frequências absolutas ( $n^{\circ}$ dias) e relativas (\%) de ocorrência das situações sinópticas para a totalidade da amostra (período analisado de 82 dias), e das situações sinópticas associadas à advecção de massas de ar Tca e Tci (para a subamostra de 53 dos 82 dias do período analisado), em Portugal Continental.

Através da análise constata-se que predominaram, em altitude (geopotencial a $500 \mathrm{hPa})$, as situações de abrigo aerológico ( $86,5 \%$ da amostra), das quais $46,3 \%$ estiveram associadas a uma circulação meridiana, em crista ou relacionadas com uma gota quente, e 40,2\% associadas a uma circulação zonal. 
Nos $13,4 \%$ dos dias em que não se observaram situações de abrigo aerológico, verificou-se a ocorrência de advecções frias em vale $(11,0 \%)$ ou em gota fria $(2,4 \%)$, que corresponderam, quase sempre, às situações sinópticas que facilitaram o combate aos incêndios florestais e consequentemente à sua extinção.

Se em altitude predominaram as situações de abrigo aerológico, à superfície, como seria expectável, dominaram condições anticiclónicas. Recorrendo mais uma vez à Tabela 5 observa-se que o anticiclone atlântico subtropical (As), com $60,6 \%$ das observações, é o predominante, seguido do atlântico misto (Aa) e do europeu $(\mathrm{Ae})$, com $21,1 \%$ e $12,7 \%$ das observações, respetivamente. Os anticiclones atlântico misto estendendo-se pela Europa Ocidental (Ao) e atlântico misto com apófise polar (Ap) tiveram uma frequência quase residual, tendo ocorrido em apenas $5,6 \%$ dos dias em análise.

A partir da análise da cartografia sinóptica do período em estudo, constatou-se, em $95 \%$ dos dias, a existência de baixas pressões térmicas sobre a Península Ibérica, com predomínio da baixa ibero-africana $(43,3 \%)$ relativamente à baixa ibérica em vale $(29,5 \%)$ e à baixa ibérica fechada $(21,8 \%)$, cujo núcleo depressionário ou eixo do vale, consoante os casos, se localizou, em $30,8 \%$ das observações em território espanhol, em $26,9 \%$ no litoral oeste de Portugal Continental e em $24,4 \%$ das observações no Norte de África.

Da ação conjunta dos vários centros de ação supracitados, de acordo com a Tabela 5, constata-se que durante o período analisado predominaram os fluxos sinópticos de este, em 32,9\% da amostra, seguidos dos de norte e noroeste, com $17,1 \%$ e $18,3 \%$, respetivamente.

No entanto, o fator mais fortemente explicativo dos valores de temperatura e de humidade relativa, à superfície, é o tipo de massa de ar que invade o território de Portugal Continental. As massas de ar que determinam a combinação de mais elevadas temperaturas com os menores valores de humidade relativa são a Tca (Tropical continental africana) e a Tci (Tropical continental ibérica), precisamente aquelas que mais frequentemente fizeram sentir a sua influência no período em análise. A frequência de ocorrência da massa de ar Tca foi de 46,3\% da amostra e da massa de ar Tci de 18,3\% da amostra, perfazendo 53 dias $(64,6 \%$ da amostra) do total de 82 dias considerados. Nos restantes 29 dias $(35,4 \%)$ do período analisado, verificou-se a influência de outros tipos de massas de ar.

Considerando só os 53 dias em que dominou a advecção das massas de ar Tca e Tci, a frequência de ocorrência de cada uma destas massas de ar foi de, respetivamente, $71,7 \%$ e $28,3 \%$ da subamostra. Para esta mesma subamostra calcularam-se as frequências de ocorrência absoluta (no dias) e relativa (\%) das diferentes situações sinópticas subjacentes ou associadas à advecção de cada uma das massas de ar Tca e Tci, cujos resultados mais relevantes se passam a analisar (Tabela 5).

Cruzando os dados das duas massas de ar mais frequentes durante o período em análise com as restantes situações sinópticas, constata-se que a massa de ar tropical continental africana (Tca) está associada, em cerca de $47 \%$ dos casos, a uma circulação de abrigo aerológico em altitude de carácter meridiano (Abm). À superfície é transportada, na maioria das observações efetuadas, pela circulação 
conjunta de um anticiclone atlântico subtropical (As) - 41,5\% - com uma depressão térmica ibero-africana (Bia) - 54,7\% -, com o núcleo centrado ou no Norte de África (naf), em $30 \%$ dos dias, ou no Litoral Oeste (lit), em 26,4\% dos dias. Esta massa de ar está maioritariamente associada a fluxos do quadrante este, nomeadamente de este $(37,7 \%)$, sudeste $(11,3 \%)$ e nordeste $(11,3 \%)$, que ao corresponderem a trajetos continentais contribuem para a explicação dos reduzidos valores de humidade relativa e das elevadas temperaturas.

Apesar de apresentar uma representatividade bastante menor do qua a massa de ar tropical continental africana (Tca), a tropical continental ibérica (Tci), corresponde à segunda mais frequente. Se a Tca estava claramente relacionada com situações de abrigo aerológico em circulação meridiana, a Tci apresenta uma frequência de ocorrência muito semelhante entre situações de abrigo aerológico em circulação zonal $(15,1 \%)$ e em circulação meridiana $(13,2 \%)$. À superfície, esta massa de ar está associada, na maior parte dos dias, à circulação conjunta de um anticiclone atlântico subtropical (24,4\%) com uma baixa pressão térmica, normalmente do tipo ibérica fechada $(11,3 \%)$ ou ibérica em vale $(9,4 \%)$, com o núcleo centrado ou no litoral oeste da península $(11,3 \%)$ ou em Espanha $(9,4 \%)$. Tal como a Tca, também esta massa ar está associada a fluxos sinópticos do quadrante este, nomeadamente de este $(9,4 \%)$ ou de nordeste $(7,6 \%)$. No entanto, os fluxos de norte também tiveram alguma relevância estatística, correspondendo a 7,6\% das observações.

\section{CONCLUSÃO}

Muito embora o número dos grandes incêndios florestais não tenha vindo a aumentar ao longo dos anos, na última década registou-se um aumento dos maiores "grandes incêndios", tendo-se vulgarizado os incêndios superiores a 100ha, pelo que se prevê que o ICNF passe, para efeitos estatísticos, a considerar GIF apenas os superiores a 1000ha.

Mesmo os maiores GIF, os superiores a 5000ha, embora ainda não sejam "vulgares" em Portugal, passaram, na última década, a fazer parte do nosso panorama dendrocaustológico pelo que, muito embora conscientes da complexa multiplicidade de fatores que os determinam, urge compreender as condições climático-meteorológicas a eles associadas.

Como síntese conclusiva da análise desenvolvida nos pontos anteriores, na figura 3 (A, B, C, D, E e F) apresentam-se algumas das situações sinópticas, selecionadas do conjunto dos 82 dias do período analisado, exemplificativas das condições geradoras da combinação de mais altas temperaturas com os mais baixos valores de humidade relativa, e por isso, também, subjacentes aos mais elevados riscos dendrocaustológicos. 
Revista Brasileira de Climatologia

\section{ISSN: 1980-055x (Impressa) 2237-8642 (Eletrônica)}

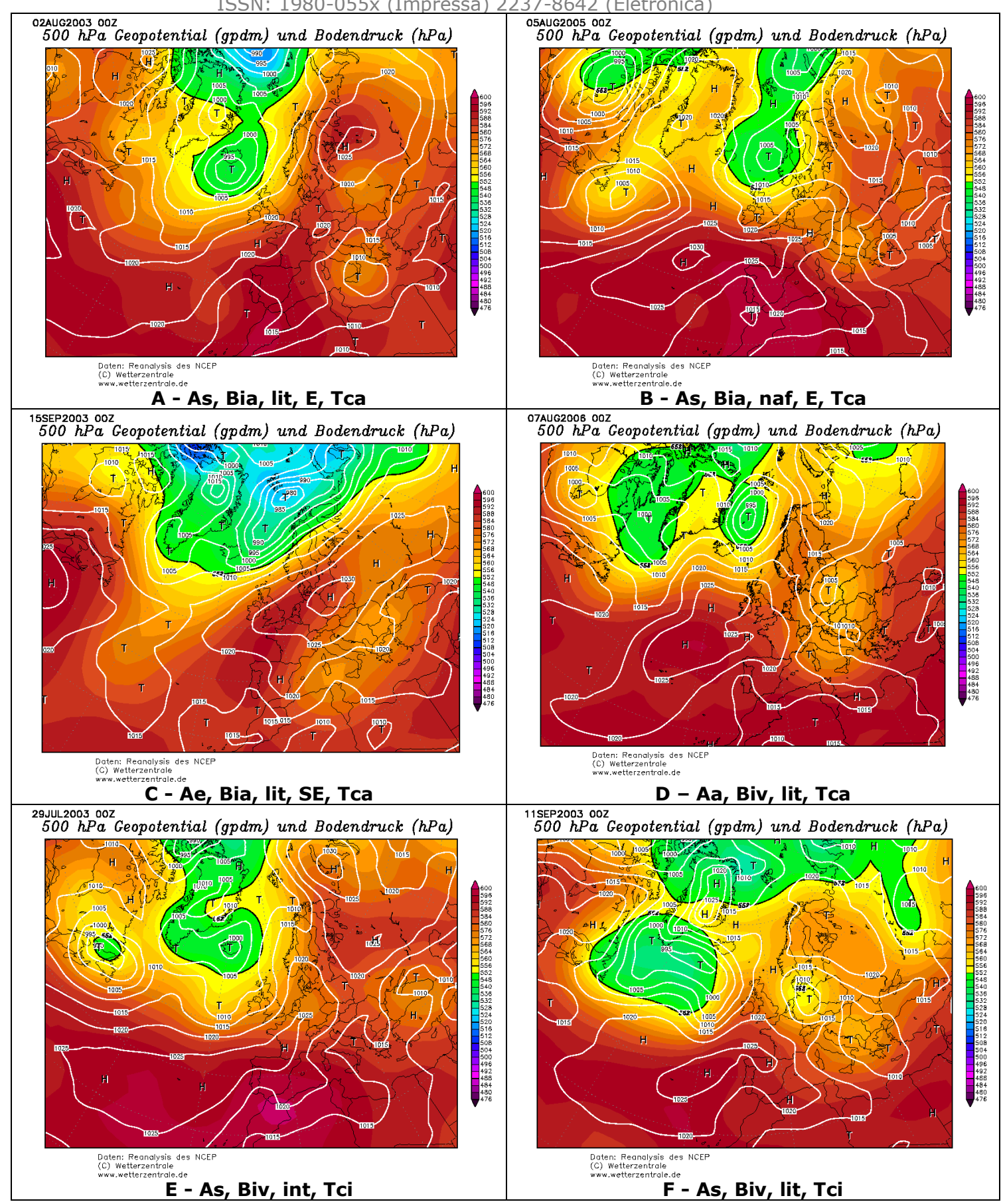

Figura 3 - Situações sinópticas mais frequentemente associadas a condições favoráveis a grandes incêndios florestais em Portugal Continental.

(Fonte: arquivo "Wetterzentrale")

Os padrões sinópticos que ilustram, relativamente semelhantes à escala do Atlântico Oriental, Europa e Mediterrâneo ocidental, apresentam "nuances" à escala mesoclimática da fachada atlântica da Península Ibérica que determinam o tipo e características, do ponto de vista termohigrométrico, dos níveis mais Ano 10 - Vol. 14 - JAN/JUL 2014 
baixos das massas de ar que invadem o território português. $O$ fator fundamental para a manutenção de elevadas temperaturas com forte secura do ar, para além da circulação conjunta dos anticiclones atlânticos ou europeus com a baixa térmica estival, é a fisionomia do campo térmico. Quando, independentemente do tipo de anticiclone com que se conjuga, ou o eixo do vale térmico ibérico ou ibero-africano se localiza no litoral português, ou no contexto deste vale se individualiza um núcleo depressionário imediatamente a sul da Península Ibérica, os fluxos de leste transportam massas de ar tropical continental, com trajeto predominantemente ibérico ou com longo trajeto sobre o noroeste de África e, nestas condições, em Portugal Continental observam-se as mais elevadas temperaturas em associação com os mais baixos valores de humidade relativa, generalizadas, inclusivamente, à faixa costeira ocidental. Quando o eixo do vale se desloca para o interior do país, ou o núcleo depressionário migra para Espanha, a direção e sentido dos gradientes barométricos na fachada atlântica da Península Ibérica fomentam a instalação do sistema de nortada oeste ibérico e a advecção das massas de ar com características termohigrométricas de superfície mais moderadas, mitigando os riscos de eclosão e propagação de incêndios florestais, mas não o suficiente para os suprimir. Tais condições só se verificam quando a dinâmica atmosférica regional favorece a convecção profunda e permite a ocorrência de precipitação significativa, o que, no período estival, só muito esporadicamente acontece.

\section{Bibliografia}

Agência para a Prevenção de Incêndios Florestais (APIF) e Instituto Superior de Agronomia (ISA), (2005). Plano Nacional de Defesa da Floresta Contra Incêndios - Proposta Técnica, Lisboa, 208 p.

Bermudez, Z., Mendes, J., Pereira, J. M. C., Turkman, K. F., Vasconcelos, M. J. P. (2009). "Spatial and temporal extreme of wildfires sizes in Portugal". International Journal of Wildland Fire 18: 983-991.

Cunha, L., Bento-Gonçalves, A. (1994). "Clima e tipos de tempo enquanto características físicas condicionantes do risco de incêndio. Ensaio Metodológico". Cadernos de Geografia 13: 3-13.

Ferreira, D. B. (1984) - Le système climatique de I'upwelling ouest Ibérique. Linha de Acção de Geografia Física, (rel. No 19), C.E.G., INIC, Lisboa, 91p.

Ganho, N. (1991). "Contribuição para o conhecimento dos tipos de tempo de Verão em Portugal - O exemplo de Coimbra". Cadernos de Geografia 10: 431513.

García-Ruiz, J. M., Lasanta, T., Ruiz-Flano, P., Ortigosa, L., White, S., González, C., Martí, C. (1996). "Land-use changes and sustainable development in mountain areas: A case study in the Spanish Pyrenees". Landscape Ecology 11: 267-277.

Lloret, F., Calvo, E., Pons, X., Díaz-Delgado, R. (2002). "Wildfires and landscape patterns in the eastern Iberian Peninsula". Landscape Ecology 17: 745-759. 
Lourenço, L. (1986). "Consequências geográficas dos incêndios florestais nas serras de xisto do centro do país". IV Colóquio Ibérico de Geografia. Actas: 943-957.

Lourenço, L. (1988). "Efeitos do temporal de 23 de Junho de 1988 na intensificação da erosão das vertentes afectadas pelo incêndio florestal de Arganil/Oliveira do Hospital". Comunicações e Conclusões do Seminário Técnico sobre Parques e Conservação da Natureza dos Países do Sul da Europa: 43-47.

Lourenço, L. (1991). "Aspectos sócio-económicos dos incêndios florestais em Portugal". Biblos LXVII: 373-385.

Lourenço, L., Bento-Gonçalves, A., Vieira, A., Nunes, Adélia, Ferreira-Leite, F (2012). Forest Fires in Portugal. Portugal Economic, Political and Social Issues. A. Bento-Gonçalves, A. Vieira (Eds.). New York, Nova Publishers: 97111.

Moreno, J. M. (1999). Forest fires: trends and implications in desertification prone areas of Southern Europe. Mediterranean Desertification: Research Results and Policy Implications 1. P. Balabanis, D. Peter, A. Ghazi, M. Tsogas (Eds.). DG Research, European_Commission EUR: 115-150.

Moreno, J. M., Vazquez, A., Velez, R. (1998). Recent history of forest fires in Spain. Large Forest Fires._J. M. Moreno (Ed.). Leiden, The Netherlands, Backhuys Publishers: 159-185.

Mouillot, F., Ratte, J. P., Joffre, R., Moreno, J. M., Rambal, S. (2003). "Some determinants of the spatio-temporal fire cycle in a Mediterranean landscape (Corsia, France) ". Landscape Ecology 18: 665-674.

Oliveras, I., Gracia, M., Moré, G., Retana, J. (2009). "Factors influencing the pattern of fire severities in a large wildfire under extreme meteorological conditions in the Mediterranean basin". International Journal of Wildland Fire 18:755-764.

Pausas, J. G. (1999). "Response of plant functional types to changes in the fire regime in Mediterranean ecosystems: a simulation approach". Journal of Vegetation Science 10: 717-722.

Pausas, J. G. (2004). "Changes in fire and climate in the eastern Iberian Peninsula (Mediterranean bassin)". Climate Change 63:337-350.

Piñol, J., Terradas, J., Lloret, F. (1998). "Climate warming and wildfire hazard and wildfire occurrence in coastal Eastern Spain". Climatic Change 38:345-357.

Ramos, C. (1986). Tipos de Anticiclones e Ritmo Climático de Portugal. Estudo de Climatologia. Linha de Acão de Geografia Física (rel. No 25), C.E.G., Lisboa, $236 \mathrm{p}$.

Ramos, C. (1987). "A influência das situações anticiclónicas no regime da precipitação em Portugal". Finisterra 22, 43: 5-38. 
Rebelo, F. (1980). "Condições de tempo favoráveis à ocorrência de incêndios florestais. Análise de dados referentes a Julho e Agosto de 1975 na área de Coimbra". Biblos LVI:653-673.

Rebelo, F. (1996). "Florestas e grandes incêndios florestais no mundo". Territorium 3: 5-10.

Rego, F. C. (1992). Land use changes and wildfires. Response of forest fires to environmental change. A.Teller, P. Mathy, J. N. R. Jeffers (Eds.). London, Elsevier: 367-373.

Rego, F. C. (2001). Florestas públicas. Direção Geral das Florestas e Comissão Nacional Especializada de Fogos Florestais, Lisboa, 105 p.

Roxo, M. J., Cortesão Casimiro, P., Soeiro de Brito, R. (1996). Inner Lower Alentejo field site: Cereal cropping, soil degradation and desertification. Mediterranean desertification and land use. C. J. Brandt, J. Thornes (Eds.). Wiley \& Sons, Chichester: 111-135.

Vélez, R. (1993). "High intensity forest fires in the Mediterranean Basin: natural and socioeconomic causes". Disaster Manage 5: 16-20.

Viegas, D. X. (1998). Weather, fuel status and fire occurrence: predicting large fires. Large Forest Fires. J. M. Moreno (Ed.). Leiden, The Netherlands, Backhuys Publishers: 31-49.

Xanthopoulos, G. (2007). "Olympic flames". Wildfire 16: 10-18. 